\title{
Violations of the Cooperative Principle: Analysis of Conversations in The Little Prince
}

Tian Dong ${ }^{1}$ and Xiuhui Huang ${ }^{2 *}$

${ }^{1}$ Professor in School of Foreign Languages, North China Electric Power University, NO 689 Road, North District, Baoding, Hebei, China

${ }^{2}$ Graduate Student in School of Foreign Languages, North China Electric Power University, NO 689 Road, North District, Baoding, Hebei, China

DOI: $10.36348 /$ SJHSS.2019.v04i09.003

| Received: 02.09.2019 | Accepted: 09.09.2019 | Published: 20.09.2019

*Corresponding author: Xiuhui Huang

Abstract

It is common to analyse literature works with the help of linguistic knowledge. The abidance and violation of the Cooperative Principle (CP) in some novels may have the an unexpected literary works. In spite of tremendous researches on The Little Prince, there are few studies analyzing the dialogues between characters in literary works from the perspective of the violation of CP. This article tries to analyz the conversations in The Little Prince, based on Grice's Cooperative principle. The aim of this article is to reveal the the features of the main characters and the deep meaning behind the literal words. Through the analysis of the violation of $\mathrm{CP}$ in the communications, readers can have a better understanding of the essence of The Little Prince. Meanwhile this study shows that in the process of appreciating literary works, it is possible to understand the text better, with the help of linguistic knowledge.

Keywords: Violations, the Cooperative Principle (CP), Four Maxims, The Little Prince.

Copyright @ 2019: This is an open-access article distributed under the terms of the Creative Commons Attribution license which permits unrestricted use, distribution, and reproduction in any medium for non-commercial use (NonCommercial, or CC-BY-NC) provided the original author and source are credited.

\section{INTRODUCTION}

Pragmatics, as one area of linguistics, has been researched by massive scholars. By studying pragmatics phenomena, those scholars established many theories, such as the Cooperative Principle. The Cooperative Principle (CP) was put forward by an American linguist Grice. This theory illustrates the rules which people need to obey during communication in order to make the conversation meaningful and constant. There are four maxims in the Cooperative Principle: the maxim of quality, the maxim of quantity, the maxim of relation as well as the maxim of manner. In order to develop Cooperative Principle, some scholars gradually perfected the theory and established some new theories, such as Levison's QIM Principle (Quantity principle, Informativeness principle, Manner principle) [1], Leech's Politeness Principle [2]. In China, the CP has been widely researched. It is mainly applied to two aspects, the $\mathrm{CP}$ and translation, the $\mathrm{CP}$ and conversation. Studying the $\mathrm{CP}$ makes a great sense to translation. Many Chinese scholars have studied the role of $\mathrm{CP}$ in translation. $\mathrm{Xu}$ and $\mathrm{Wu}$ [3] have claimed there is no doubt that $\mathrm{CP}$ plays a guiding role in translation of business English, and the $\mathrm{CP}$ is in line with the four basic principles which guide the business English translation. Xiao [4] advocates that in literary translation, CP could keep the process of translation, measure the effects of translation, remind translators of the faithful reproduction of the conversational implicature of the original texts. Han [5] applied the Cooperative Principle to the translation of legal text, and he found that the $\mathrm{CP}$ played the directive role in the translation of legal text. Han emphasized the importance of the Maxim of Manner. As for the application of $\mathrm{CP}$ in conversation, readers can understand the conversational implicature behind the text from a deeper perspective, so as to better grasp the characteristics of the characters and the main ideas the author wants to express, with the help of the violation of the CP [6]. Liu [7] thought readers could not only understand the language skill and the writing arrangement better, but also improve our cognition to the literary works to a higher level. Li [8] analyzed conversations under the violation of the $\mathrm{CP}$, and she reveals the authentic pragmatic purpose implied in the discourse.

Since the CP is of great importance in translation and conversation, this paper makes an attempt to apply CP to the analysis of the conversations in The Little Prince. The author tries to analyse the violations of the four $\mathrm{CP}$ maxims in the conversations, with the aim to reveal the characters' personalities and the implied idea behind the text. 


\section{LITERATURE REVIEW \\ Previous Studies of The Little Prince}

The Little Prince is a famous short story of French children's literature written by Anthony De Saint- Exupery in 1942. The protagonist of this book is a little prince, coming from the outer planet. In the book, a pilot narrates the story of the adventures of the little prince as he travels from his own planet to the Earth. From the perspective of the little prince as a child, the author reveals the emptiness, blindness and foolishness of the adults, and writes out the loneliness of human being and the wandering fate with simple and innocent language. At the same time, the author criticizes the cash nexus and eulogizes the true and the beautiful.

Since it was published, The Little Prince has been researched by scholars from home and abroad. Foreign scholars studied The Little Prince in terms of translation and the novel's enlightenment to humanity. Zimmer [9] discusses the translation challenges in The Little Prince. Lemay [10] discussed the attention of the world of autism. Chinese researchers mainly focus on the symbolic meaning and the translation of The Little Prince. Some scholars, such as $\mathrm{Hu}$ [11] and Sun [12], research the symbolic meanings in The Little Prince. $\mathrm{Hu}$ [11] illustrated three kinds of symbolic meanings in novels. The first kind of symbol is direct and transparent. The second kind of symbol can be understood after the deep and reduplicative thinking. The third kind of symbol is quite hard to understand because readers should learn the social and cultural background knowledge. Sun [12] also stated three kinds of symbols in The Little Prince, the people images, the animal images and the plant images. Li [13] and Zhao [14] both found that the translation had better start from children's point of view and conform to the aesthetic experience of children readers.

From the review of literature, it is concluded that both Chinese and overseas researchers have studied The Little Prince in terms of translation. However, there is almost few people study The Little Prince from the perspective of the Cooperative Principle. This paper can analyze The Little Prince from the new point of view and help readers understand this novel better.

\section{The Cooperative Principle}

Grice thinks that there exists certain regularity in conversation. And the regularity is called the Cooperative Principle, which includes four maxims named as the maxim of quantity, the maxim of quality, the maxim of relation as well as the maxim of manner [15].

The maxim of quantity is related to the quantity of information to be provided, and the maxim is as below:

- Your contribution should be as informative as it is demanded.
- Your contribution should not be more informative than it is demanded.

The maxim of quality is related to the truth of information to be provided, and the maxim is as below:

- Your contribution should be what you think is true.

- Your contribution should be what you have adequate evidence.

The category of the maxim of relation is related to the relevance of information to be provided, and falls a single maxim, namely: To be relevant with the topic.

The category of the maxim of manner is related to the proper way of information to be provided, and the maxim is as below:

- Obscurity of expression should be avoided.

- Ambiguity should be avoided.

- Unnecessary prolixity should be avoided.

- Be orderly [15].

\section{VIOLATION OF COOPERATIVE PRINCIPLE IN THE LITTLE PRINCE}

\section{(1) The Violation of the Maxim of Quantity}

The following examples of dialogues will illustrate two kinds of violations of the maxim of quantity.

Example 1: “Then you are thirsty, too?" I demanded. But he did not reply to my question. He merely said to me:

$$
\text { "Water may also be good for the heart..." }
$$

\section{The Little Prince}

This is a dialogue between the author and the little prince. In the demand of water, the author asks the little prince whether he is thirsty, but the little prince says, "Water may also be good for the heart..." As for the maxim of quantity, speakers should firstly provide enough information so that the other side can understand the meaning. However, the little prince fails to offer sufficient information. The author may be puzzled about the little prince reply. Because the little prince comes from the outer space, his physical condition is different from human. He can live without water but in his opinion, water may be good for the heart. The little prince take granted that the author knows he is not thirsty, so he only gives his opinion about water. Here the little prince only offers the information beyond what the author wants him to reply, so the little prince violates the maxim of quantity with the insufficient information. It is the inadequate information that illustrates the distinctiveness of the little prince, arousing the readers' deep thinking.

Example 2: “Ah! I am scarcely awake. I beg that you will excuse me. My petals are still all disarranged..."

But the little prince could not restrain his

admiration: 
"Oh! How beautiful you are!"

"Am I not?" the flower responded, sweetly. "And I was born at the same moment as the sun..."

\section{-The Little Prince}

This is a dialogue between the little prince and the rose. The rose just blossoms, so she says, "I am scarcely awake" but words like "I beg that you will excuse me. My petals are still all disarranged" and "And I was born at the same moment as the sun" are all not necessary for the dialogue. Because the rose does not do anything wrong but only has her petals disarranged, there is no need for her to apologize. Then the little prince praises the rose for her beauty, but the rose says she is born with the sun. The flower provides too much unnecessary information to the little prince, so she violates the maxim of quantity. However, due to the extra information offered by the rose, the arrogance, conceit, and manipulation of the flower are revealed to the readers, which to some extent, leading to the departure of the little prince in the later plot.

From the above examples, the conclusion can be drawn that the violations of the maxim of quantity in the little prince can result in some literal effects, such as revealing the typical feature of the characters, arousing the imagination of readers and laying a foundation for the later plots.

\section{(2) The Violation of Maxim of Quality}

The following examples of dialogues will illustrate two kinds of violations of the maxim of quality.

Example 3: "A sheep-- if it eats little bushes, does it eat flowers, too?" finds in its reach."

"A sheep," I answered, "eats anything it

"Even flowers that have thorns?"

"Yes, even flowers that have thorns."

"Then the thorns-- what use are they?"

"The thorns are of no use at all. Flowers have thorns just for spite!"

"Oh, no!" I cried. "No, no, no! I don't believe anything. I answered you with the first thing that came into my head. Don't you see-- I am very busy with matters of consequence!"

\section{-The Little Prince}

This is a dialogue between the author and the little prince. The little prince mainly has two questions. One is what the sheep eats and the other is what the thorns are used for. The author replies that the sheep eats anything it finds in its reach and that flowers have thorns just for spite, respectively. The author answers the question with what he think may be not true, because in the following plots, he says that he does not believe anything and he answers the question with the first thing that came into him head. Therefore the author just answers the little prince the things that he never believes and that just jump out in his mind. Therefore the author violates the maxim of quality by saying what he does not think is true. Nonetheless, on account of the violation of the maxim of quality, the impatience of the author is unfolded when the author is restless with anxiety over the broken machine. Then the author reflects his impatience by the perfunctory answer.

Example 4: Just so, you might say to them: "The proof that the little prince existed is that he was charming, that he laughed, and that he was looking for a sheep. If there is anybody who wants a sheep, it will be a proof that he exists." And what good would it do to tell them that? They would shrug their shoulders, and treat you like a child. But if you said to them: "The planet he came from is Asteroid B612 ," then they would be convinced, and leave you in peace from their questions.

\section{The Little Prince}

This is an imaged dialogue between the little prince and the author. In this dialogue, "they" refers to the adults. The author intends to show the existence of the little prince by the subjective evidences, but the adults would be only convinced by the objective evidences. "The proof that the little prince existed is that he was charming, that he laughed, and that he was looking for a sheep. If there is anybody who wants a sheep, it will be a proof that he exists." and "The planet he came from is Asteroid B-612", which are two kinds of evidences used to prove that the little prince does exist. The first reason is that the little prince is charming and he laughs, and that he wants a sheep. When the author offers the first reason to the adults, he will violate the maxim of quality, because he offers inadequate evidence to provide information. The second reason is that the little prince comes from the planet called Asteroid B-612. When the author offers this reason to the adults, he obeys the maxim of quality, because he offers adequate evidence. Generally speaking, both sides of the communicators should follow the maxim of quality so we tend to choose the second reason to prove the existence of the little prince. However, the author here even approves the first evidence. Superficially, the adults are right and the author should propose the second reason to convince them. However, actually, the author supports the violation of maxim of quality. Therefore he would choose the first reason. Here is a comparison of the thinking patterns between the adults and the children. Children tend to believe the first reason, because the children are full of imagination, flexibility and innocence, while the adults believe the second reason, 
because they only believe reality and truth. With this comparison, the author intends to blame the adults for their lack of vapidity, blindness, and stereotype.

From the examples above, the author violates the maxim of quality, in order to highlight the personalities of the characters as well as the main idea.

\section{(3) The Violation of Maxim of Relation}

The following example will illustrate the violation of the maxim of relation.

Example 5: "My little man, where do you come from? Where is your home and where do you want to take my sheep to? After a reflective silence he answered: "The thing that is so good about the box you have given me is that at night it can be used as his house."

"That is so. And if you are good I will give you a string, too, so that you can tie him during the day."

\section{-The Little Prince}

This is a conversation between the author and the little prince. The author intends to get the information about the little prince. However the little prince just offers some unrelated information, by praising the benefits of the box. The little prince violates the maxim of relation, for two reasons. Firstly, he just buries himself in the happiness of getting a sheep and a box. Secondly, he avoids answering the author's question with the artful words of shifting the topic. And later the author indeed changed his topic and the topic is led away by the little prince. Violation of the maxim of relation often occurs when either side of the communicators is indifferent to the topic or when either side avoids offering the key information.

\section{(4) The Violation of Maxim of Manner}

The following example will illustrate the violation of the maxim of manner.

Example 6: "Why are you drinking?" demanded the little prince.

"So that I may forget," replied the tippler.

"Forget what?" inquired the little prince, who already was sorry for him.

"Forget that I am ashamed," the tippler confessed, hanging his head.

"Ashamed of what?" insisted the little prince, who wanted to help him.

"Ashamed of drinking!" The tippler brought his speech to an end.

-The Little Prince

This is a conversation between the little prince and a drunker. The little prince just wants to know why the drunker drinks, but the drunker explains the key words "forget", "ashamed" and "drinking"one by one.
Therefore the little prince is still confused about why he drinks. The drunker here violates the maxim of manner with the obscurity expressions. By saying unclear words, the state of the drunker is distinctive, which also shows the emptiness, blindness, loneliness of adults, as the drunker is a symbol of some kind of adults.

Example 7: "What! You dropped down from the sky?"

"Yes," I answered, modestly.

"Oh! That is funny!"

Then he added: "So you, too, come from the sky! Which is your planet?" -The Little Prince

In this example, "You dropped down from the sky?" this sentence causes ambiguity. Dose the author come from the sky or drop from the sky with his plane? The author thinks "drop down" is that he and his plane drop down from the sky, but in the little prince's mind "drop down" means that the author comes from the sky just as him. The author at the beginning misunderstands his words but the latter words "So you, too, come from the sky! Which is your planet?" dissolves the misunderstanding. The violation here matches with the prince's and the author's experiences. With different experiences, the author and the little prince have different understanding of the words "dropped down from the sky".

Example 8: "Those are the orders," replied the lamplighter.

"I do not understand," said the little prince.

"There is nothing to understand," said the lamplighter. "Orders are orders."

The Little Prince

In this example, the little prince wants the lamplighter to explain what the orders are, but the lamplighter explains that the orders are orders. The lamplighter uses unnecessary prolixity to explain the orders, so he violates the maxim of manner. By using the violation here, the author wants to reveal the blindness of some adults, because they only do things without knowing the reason why they should do.

Example 9: "Here it is. Let me go on by myself."

And he sat down, because he was afraid. Then he said, again:

"You know-- my flower... I am responsible for her. And she is so weak! She is so naive!

She has four thorns, of no use at all, to protect herself against the entire world..."

I too sat down, because I was not able to stand up any longer.

"There now-- that is all..."

The Little Prince 
In this case, because the little prince is afraid of the unknown future, his words become disorder. The logic relation of his words is not clear. The right order of the word should be "the flower only has four thorns to protect herself, so she is weak and naive. Therefore the little prince is responsible for the flower". In general, the words should be arranged in order according to their logic relations. Because he is upset and afraid, his words are incoherent in his speech, causing the violation of maxim of manner.

\section{CONCLUSION}

In daily communication, following the Cooperative Principle can make the conversation meaningful and smooth. However in literary works, the characters sometimes violate the Cooperative Principle to achieve specific literary effects. This paper reveals the literary effects by analyzing the violations of the four maxims in The Little Prince. There are some violations of the $\mathrm{CP}$ in the conversations between the characters in The Little Prince, which highlights the features of the characters, and lays foundation for the development of the plots, and attracts the thread of the plots and sublimate the main idea.

Although, there are many researches on The Little Prince, this paper proves it is possible and reasonable to appreciate the literary works with the help of linguistic knowledge, such as the CP. The CP can offer us a better and deeper understanding of the text, because we can analyze the conversations and languages through the tiny details.

\section{REFERENCES}

1. Levinson, S. C. (2004). Pragmatics. Beijing: Beijing Foreign Language Teaching and Research Press.

2. Leech, G. N. (1983). Principles of Pragmatics. London: Longman Group Ltd.

3. Xu, X., \& Wu, F. (2008). The Cooperative Principle and the Basic Principles of Business
English Translation. Chinese Science \& Technology Translators Journal, (2): 24-27.

4. Xiao, M. (2009). On the Application of the Cooperative Principle to Literary Translation. Foreign Languages and Their Teaching, (1): 6063.

5. Han, J. (2014). Directive Functions of the Cooperative Principle on the Translation of Legal Text. Foreign Language Research, (5): 77-80.

6. Gong, G., \& Zhang, Y. (2010). The Violation of the Cooperative Principle in Conversations of Thunderstorm, Masterpieces Review, (4): 104110.

7. Liu, X. (2016). The Cooperative Principle: the Dialogues of Characters in The Merchant of Venice. Language Planning, (32): 97-98.

8. Sedov, L. I. (2018). Similarity and dimensional methods in mechanics. CRC press.

9. Zimmer, B. (2016). The Translation Challenges of "The Little Prince". Wall Street Journal Online Edition.

10. Lemay, J. F., \& Eastabrook, G., \& MacKenzie, H. (2017). The Little Prince: a glimpse into the world of autism? Arch Dis Child.

11. $\mathrm{Hu}, \mathrm{Y}$. (1998). The Symbolic Significance in The Little Prince. Foreign Literature Review, (01): 33-38.

12. Sun, J. (2012). On the Symbolic Significance of The Little Prince. Literatures, (11):192-194.

13. Li, Y. (2010). The Translation of Children's Literature from the Perspective of Expectation---the Chinese Translation of The Little Prince. Literatures, (10):144-145.

14. Zhao, S. (2018). On the Translation of Children's Literature from the Perspective of Readers' Reception----A Comparative Analysis of two Chinese Versions of The Little Prince. Sinogram Culture, (15):58-59.

15. Grice, P. (1975). Logic and conversation. In Cole, P., \& Morgan, J. (eds). Syntax and Pragmatics. New York: Academic Press. 